pubs.acs.org/OrgLett

\title{
Enantioselective Synthesis of (-)-Acetylapoaranotin
}

\author{
Haoxuan Wang, Clinton J. Regan, Julian A. Codelli, Paola Romanato, Angela L. A. Puchlopek-Dermenci, \\ and Sarah E. Reisman*(0)
}

The Warren and Katharine Schlinger Laboratory for Chemistry and Chemical Engineering, Division of Chemistry and Chemical Engineering, California Institute of Technology, Pasadena, California 91125, United States

\section{Supporting Information}

ABSTRACT: The first enantioselective total synthesis of the epipolythiodiketopiperazine (ETP) natural product (-)-acetylapoaranotin (3) is reported. The concise synthesis was enabled by an eight-step synthesis of a key cyclohexadienol-containing amino ester building block. The absolute stereochemistry of both amino ester building blocks used in the synthesis is set through catalytic asymmetric (1,3)-dipolar cycloaddition reactions. The formal syntheses of (-)-emethallicin E and (-)-haemotocin are also achieved through the preparation of a symmetric cyclohexadienol-containing diketopiperazine.

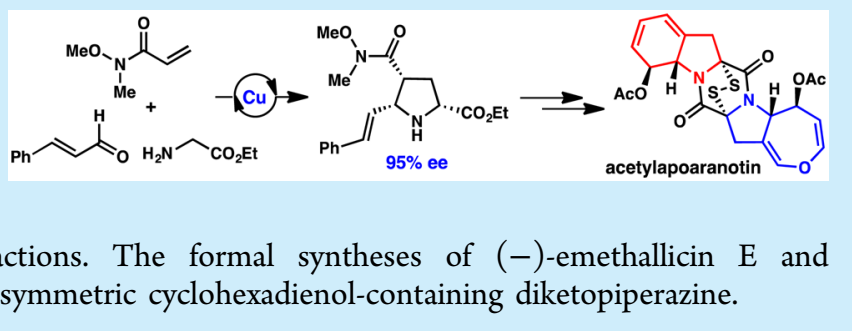

$\mathrm{T}^{\mathrm{s}}$ he epipolythiodiketopiperazine (ETP) fungal metabolites are fascinating natural products in terms of both their structural features and biological properties. ${ }^{1}$ Although they are biosynthetically $^{2}$ related to diketopiperazines (DKPs)-a widespread and structurally diverse family of natural products produced by plants, bacteria, and fungi ${ }^{3}$-ETPs are exclusively isolated from fungal species. In many cases, they are hypothesized to serve as virulence or defense factors and exhibit various antimicrobial, antiviral, and anticancer activities. ${ }^{1}$ The disulfide is the key structural feature that confers bioactivity; although many of the corresponding $S$-methylated compounds have been isolated, these compounds typically have greatly reduced cytotoxicities. ${ }^{4}$

Given their interesting structures and biological activities, the ETPs have attracted considerable interest from synthetic chemists (see Figure 1 for representative structures). ${ }^{5}$ Pioneering synthetic studies were conducted by Kishi and co-workers, resulting in the first total synthesis of gliotoxin (2) in 1976. ${ }^{6,7}$ More recently, Nicolaou and colleagues reported a general approach to the cyclohexadienol-containing ETPs, resulting in the syntheses of gliotoxin (2), emethallicin E (4), and several other structurally related natural and non-natural ETPs from commercially available L- $N$-Boc-tyrosine. ${ }^{8}$ Our laboratory published the first total synthesis of a dihydrooxepinecontaining ETP, acetylaranotin (1), ${ }^{9,10}$ which was followed closely by a synthesis from Tokuyama and co-workers. ${ }^{11}$ In addition, a number of elegant syntheses of pyrroloindolinecontaining ETPs have been reported. ${ }^{12}$

As part of our efforts to develop a unified strategy to prepare members of both the dihydrooxepine-containing and cyclohexadienol-containing ETPs, we became interested in acetylapoaranotin (3), the heterodimeric natural product that links these two subfamilies. 3 was first reported by Neuss and coworkers as part of their studies characterizing the structure and biological activities of metabolites produced by the fungus Arachniotus aureus. ${ }^{5 \mathrm{~h}}$ Decades later, Yang and co-workers isolated 3 from Aspergillus sp. KMD 901 and determined that it induces apoptosis in HCT116 colon cancer cells. ${ }^{13}$ Here, we report the first total synthesis of 3 , which was enabled by an eight-step, enantioselective synthesis of a key amino acid building block, 7 .

Retrosynthetically, our approach to 3 called for DKP formation and sulfenylation as the final steps of the synthesis, thus reducing the synthetic challenge to the preparation of the corresponding amino acid building blocks 6 and 7, the former of which we had previously prepared during our synthesis of (-)-acetylaranotin (1) (Figure 1). ${ }^{9}$ The silyl-protected cyclohexadienol 7 was envisioned to arise from siloxyenone 8, which we expected to be available in short order from pyrrolidine 9 . In analogy to our synthesis of 1,9 would be prepared from the product of a $\mathrm{Cu}$-catalyzed asymmetric $(1,3)$-dipolar cycloaddition $^{14}$ using simple starting materials: acrylamide 10, cinnamaldehyde (12), and ethyl glycinate (11). Moreover, in the long term, we anticipate that intermediates 7 and 8 could enable the synthesis of additional ETPs, including epicorazine A (5, Figure 1). . $^{5 j}$

Our studies began with the synthesis of cyclohexadienol 7 (Scheme 1). To this end, $\mathrm{Cu}(\mathrm{I}) /$ brucin-OL-catalyzed $^{14}(1,3)$ dipolar cycloaddition between Weinreb amide 10 and the imine derived from cinnamaldehyde (12) and ethyl glycinate (11) provided pyrrolidine 13 in $42 \%$ yield and $95 \%$ enantiomeric excess (ee) on $15 \mathrm{mmol}$ scale. The modest yields result in part from the propensity of pyrrolidine 13 to engage in a second $(1,3)$-dipolar cycloaddition to give the corresponding pyrrolizidine. ${ }^{15}$ Although the yield for this transformation was slightly lower than that obtained using tert-butyl acrylate (as in our synthesis of acetylaranotin ${ }^{9}$ ), it was advantageous to obtain Weinreb amide 13 directly from the dipolar cycloaddition and avoid subsequent functional group interconversions. Following protection of pyrrolidine $\mathbf{1 3}$ as the 2-(trimethylsilyl)ethyl carbamate (Teoc, 14), we sought to execute a chemoselective

Received: February 17, 2017

Published: March 28, 2017 


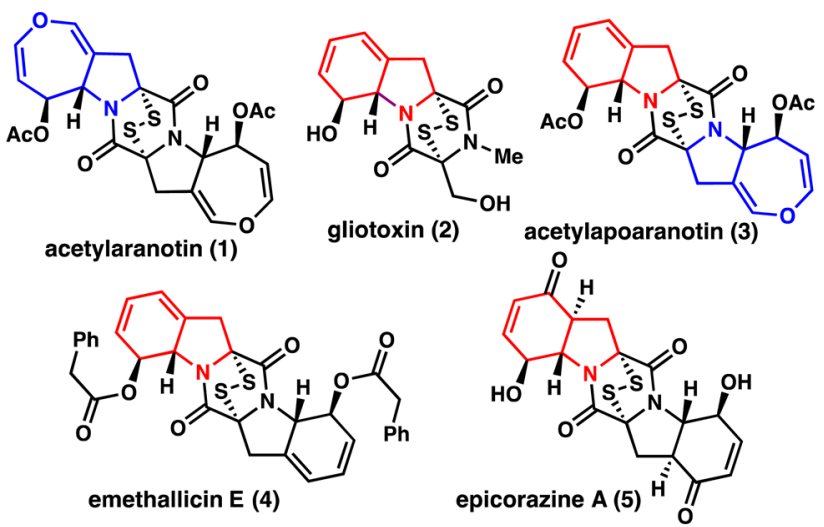

Retrosynthetic analysis:
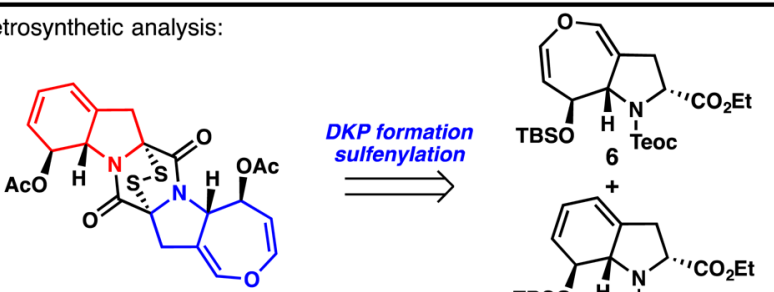

acetylapoaranotin (3)<smiles>C=CCC(C)=O</smiles><smiles>CCOC(=O)[C@@H]1C[C@H](CC)[C@@H](/C=C/c2ccccc2)N1[14C](=O)OC</smiles>

$\stackrel{\text { RCM, [O] }}{\longleftarrow}$ 9 asymmetric $\sqrt{\text { cycloaddition }}$<smiles>C=CC(=O)N(C)OC</smiles><smiles>CCOC(=O)CN</smiles>

11

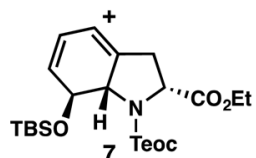

7 Teoc

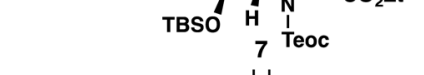

Figure 1. Representative ETP natural products and retrosynthetic analysis.

1,2-addition of allyl magnesium chloride to the Weinreb amide. As expected, this transformation proved challenging due to competing addition of the organometallic reagent to the ethyl ester. Nevertheless, by carefully controlling the equivalents of the Grignard reagent and maintaining cold temperatures through dropwise addition, allyl ketone 9 could be isolated in $51 \%$ yield on a multigram scale.

Exposure of diene 9 to the second generation HoveydaGrubbs catalyst (HG-II $)^{16}$ yielded ring-closing metathesis product 15 in good yield (Scheme 1). $\beta, \gamma$-Unsaturated enone 15 was immediately treated with dimethyldioxirane (DMDO) to provide the epoxide, which was subsequently heated in a toluene slurry of silica gel to afford $\gamma$-hydroxy enone $\mathbf{1 6}$ as an inseparable 6.5:1 mixture of diastereomers. Following protection of alcohols $\mathbf{1 6}$ as the TBS ethers, the diastereomers could be separated using silica gel chromatography to furnish 8 in $72 \%$ isolated yield. Conversion of 8 to the enol triflate was followed by palladium-catalyzed reduction ${ }^{11 a}$ to arrive at TBSprotected cyclohexadienol 7 in 8 steps from ethyl glycinate.

At this stage, a sequential peptide coupling was employed to prepare the diketopiperazine (Scheme 2). Thus, saponification of the ethyl ester of 7 with trimethyltinhydroxide afforded carboxylic acid 17. ${ }^{17}$ Amide coupling between acid 17 and dihydrooxepine-containing amine $\mathbf{1 8}$ was achieved in high yield using BOP-Cl. Treatment of dipeptide 19 with TBAF.

Scheme 1. Enantioselective Synthesis of 7

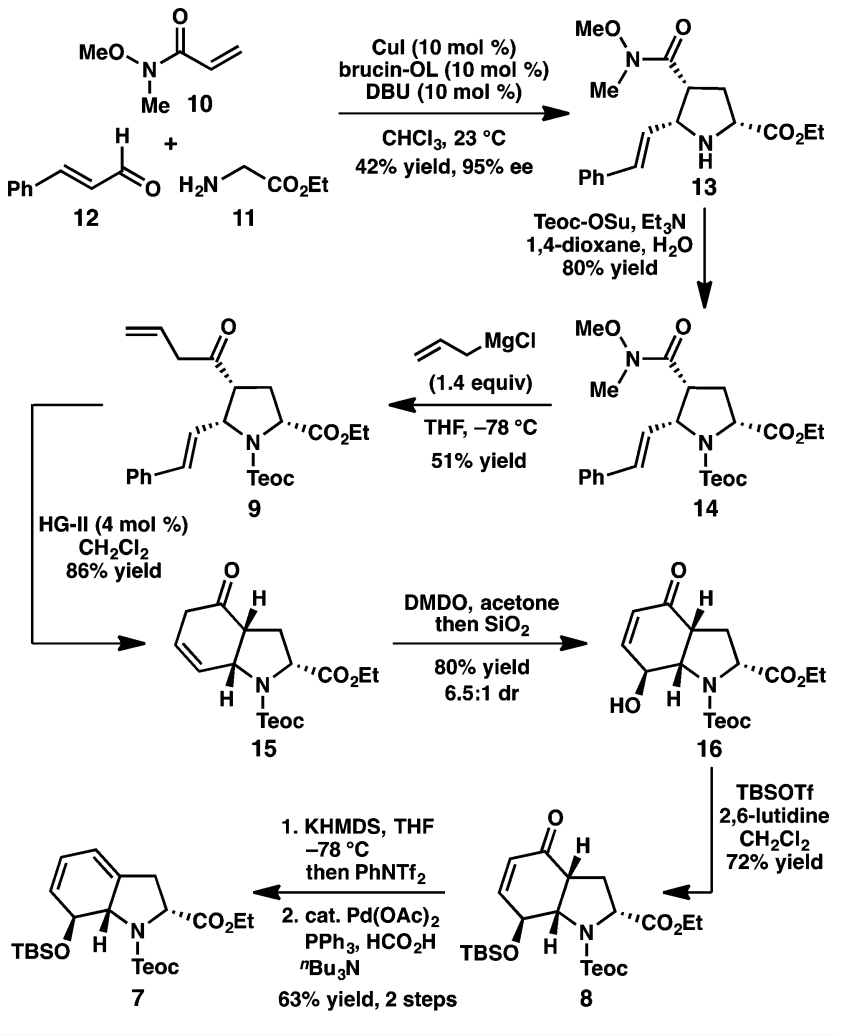

Scheme 2. Completion of the Synthesis of (-)-Acetylapoaranotin (3)
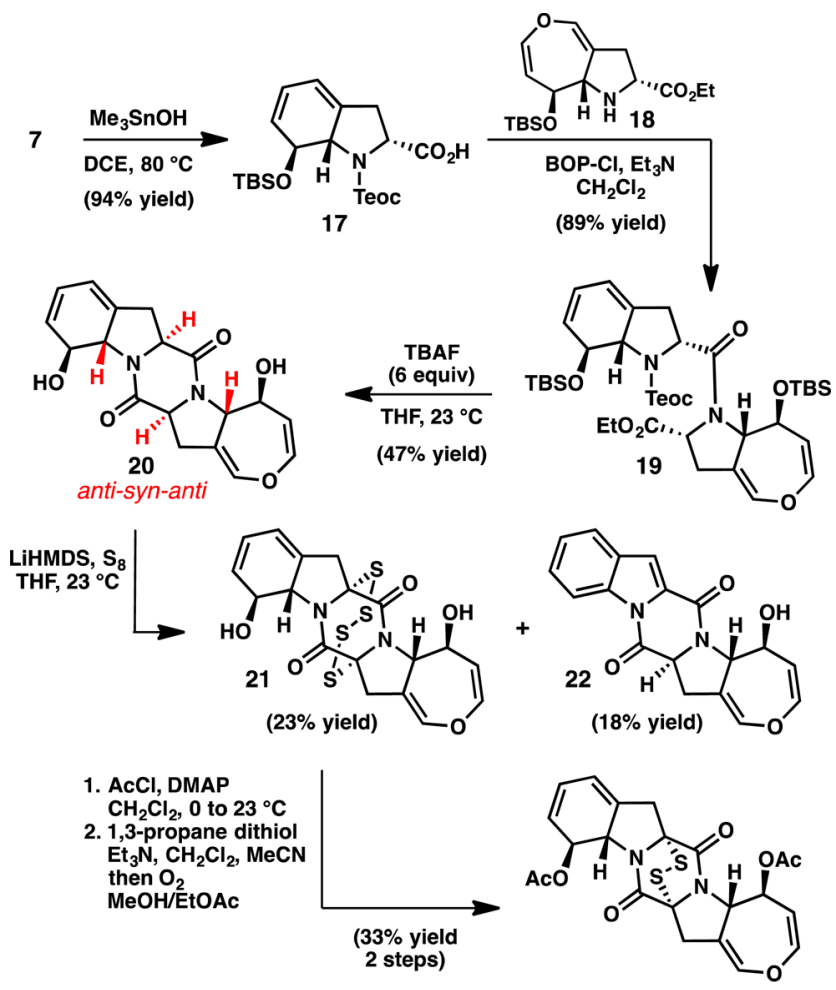

(-)-acetylapoaranotin (3)

$\left({ }^{t} \mathrm{BuOH}\right)_{4}$ in acetonitrile at $60{ }^{\circ} \mathrm{C}$ - the conditions developed for global desilylation and DKP formation in our synthesis of acetylaranotin ${ }^{9}$ - led to elimination of the dienyl alcohol to give the corresponding arene. ${ }^{18}$ This undesired reactivity could be 
mitigated when the reaction was conducted with excess TBAF at room temperature, providing diol 20 in $47 \%$ yield. In addition to removal of the three silyl protecting groups with concomitant DKP formation, these conditions result in epimerization to give the thermodynamically preferred antisyn-anti diastereomer (stereochemistry highlighted in red) of the central diketopiperazine. The somewhat moderate yield results from an inability to completely prevent the formation of arene side products under basic conditions; the corresponding syn-syn-syn diastereomer was not detected.

Given the sensitivity of diol $\mathbf{2 0}$ to base, it was unsurprising that the subsequent sulfenylation proved challenging. Ultimately, tetrasulfide $\mathbf{2 1}$ could be isolated in $\mathbf{2 3 \%}$ yield using the protocol developed by Nicolaou et al., ${ }^{8 a}$ which employs LiHMDS as the base; indole 22 was also obtained in $18 \%$ yield. Use of NaHMDS instead of LiHMDS provided substantially lower yields. Tetrasulfide $\mathbf{2 1}$ was converted to the natural product, 3 , by diacetylation, reduction to the dithiol, and aerobic oxidation to the disulfide. This represents the first synthesis of acetylapoaranotin, which proceeds in 18 steps (longest linear sequence) from ethyl glycinate. ${ }^{19}$ The propensity to form indole $\mathbf{2 2}$ highlights a unique challenge presented by heterodimeric ETP 3: the cyclohexadienol fragment is sensitive to base, while the dihydrooxepine moiety is unstable to acid, therefore strictly limiting the tactics suitable for disulfide formation.

In addition to preparing acetylapoaranotin, we also sought to demonstrate that this method could be used to prepare the C2symmetric diketopiperazines found in natural products such as 4 and 27. Global deprotection of diene 7 was effected by treatment with excess TBAF, and hydrolysis with aq. $\mathrm{LiOH}$ afforded amino acid 24 (Scheme 3). Dimerization using peptide coupling reagent PyBroP furnished diketopiperazine 25, which was epimerized to the thermodynamically favored anti-syn-anti diastereomer 26 with cesium carbonate in $\mathrm{MeOH}$. Diketopiperazine $\mathbf{2 6}$ has been utilized by Nicolaou and co-workers to prepare both emethallicin E (4) and haemotocin (27) in three

Scheme 3. Synthesis of DKP 26, an Intermediate in the Formal Syntheses of Emethallicin E (4) and Haematocin (27)

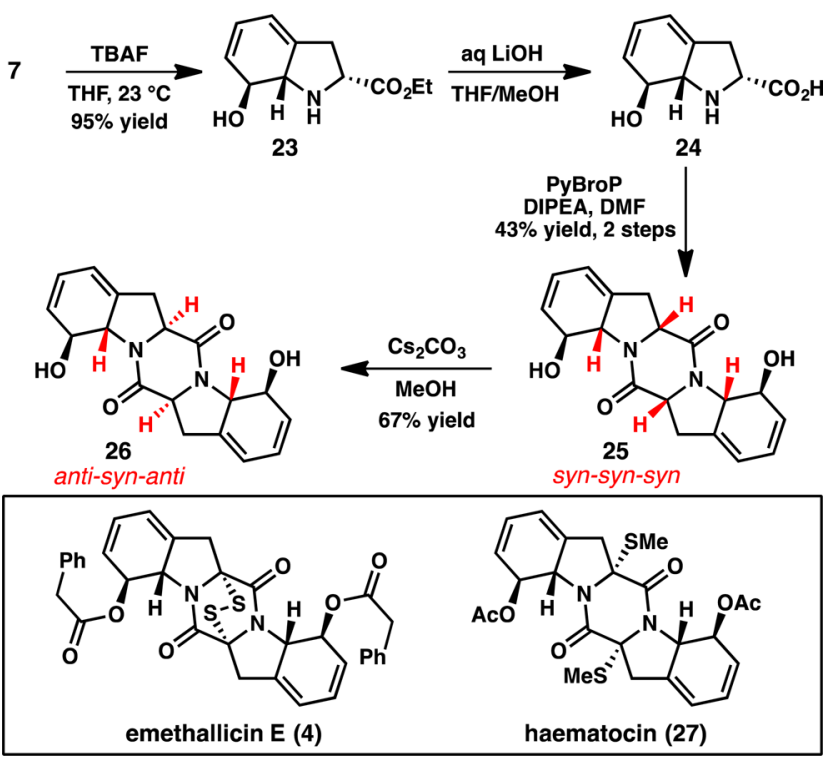

additional steps; thus, the synthesis of $\mathbf{2 6}$ represents the formal syntheses of these natural products. ${ }^{8 a}$

In summary, we have developed an efficient eight-step strategy to synthesize cyclohexadienol 7 , a key amino acid building block that enabled the first total synthesis of (-)-acetylapoaranotin. An important feature of our strategy is that the absolute stereochemistry of both the dihydrooxepine and cyclohexadienol amino acid building blocks is set through catalytic asymmetric (1,3)-dipolar cycloaddition reactions. We have also demonstrated that 7 can be used to prepare a dimeric cyclohexadienol-containing diketopiperazine, which represents the formal syntheses of $(-)$-emethallicin $\mathrm{E}$ and $(-)$-haemotocin. Intermediates in this synthetic route could potentially be utilized to prepare other structurally related 6,5-bicyclecontaining ETP natural products, for example, $(-)$-epicorazine $\mathrm{A}^{5 j}$ (4, Figure 1) and (+)-epicoccin A. ${ }^{20}$ Synthetic studies directed toward realizing these goals are ongoing in our laboratory.

\section{ASSOCIATED CONTENT}

\section{Supporting Information}

The Supporting Information is available free of charge on the ACS Publications website at DOI: 10.1021/acs.orglett.7b00418.

Experimental data, characterization information, and spectra (PDF)

\section{AUTHOR INFORMATION}

\section{Corresponding Author}

*E-mail: reisman@caltech.edu. ORCID

Sarah E. Reisman: 0000-0001-8244-9300

Notes

The authors declare no competing financial interest.

\section{ACKNOWLEDGMENTS}

We gratefully acknowledge Dr. Scott Virgil and the Caltech Center for Catalysis and Chemical Synthesis for access to analytical equipment, and Dr. David VanderVelde for assistance with NMR structure analysis. We thank Materia, Inc. and Sigma-Aldrich for donations of chemicals. We also thank Amy McCarthy, Geanna Min, and Madeleine Kieffer of Caltech for the preparation of synthetic intermediates. Fellowship support was provided by the Department of Defense (DoD) through the National Defense Science \& Engineering Graduate Fellowship Program (J.A.C.), the NSF Graduate Research Fellowship Program (J.A.C., Grant No. DGE-0703267), and the Swiss National Science Foundation (P.R.). S.E.R. is an American Cancer Society Research Scholar and Heritage Medical Research Institute investigator. Financial support from the NIH (NIGMS RGM097582A), the American Cancer Society, the Research Corporation Cottrell Scholar program, and DuPont is gratefully acknowledged.

\section{REFERENCES}

(1) For reviews of the chemistry and biology of ETP natural products, see: (a) Waring, P.; Eichner, R. D.; Müllbacher, A. Med. Res. Rev. 1988, 8, 499. (b) Gardiner, D. M.; Waring, P.; Howlett, B. J. Microbiology 2005, 151, 1021. (c) Patron, N. J.; Waller, R. F.; Cozijnsen, A. J.; Straney, D. C.; Gardiner, D. M.; Nierman, W. C.; Howlett, B. J. BMC Evol. Biol. 2007, 7, 174. (d) Jiang, C.-S.; Guo, Y.- 
W. Mini-Rev. Med. Chem. 2011, 11, 728. (e) Iwasa, E.; Hamashima, Y.; Sodeoka, M. Isr. J. Chem. 2011, 51, 420. (f) Welch, T. R.; Williams, R. M. Nat. Prod. Rep. 2014, 31, 1376.

(2) (a) Scharf, D. H.; Habel, A.; Heinekamp, T.; Brakhage, A. A.; Hertweck, C. J. Am. Chem. Soc. 2014, 136, 11674. (b) Guo, C.-J.; Yeh, H.-H.; Chiang, Y.-M.; Sanchez, J. F.; Chang, S.-L.; Bruno, K. S.; Wang, C. C. J. Am. Chem. Soc. 2013, 135, 7205. (c) Scharf, D. H.; Remme, N.; Habel, A.; Chankhamjon, P.; Scherlach, K.; Heinekamp, T.; Hortschansky, P.; Brakhage, A. A.; Hertweck, C. J. Am. Chem. Soc. 2011, 133, 12322. (d) Scharf, D. H.; Remme, N.; Heinekamp, T.; Hortschansky, P.; Brakhage, A. A.; Hertweck, C. J. Am. Chem. Soc. 2010, 132, 10136. (e) Gardiner, D. M.; Howlett, B. J. FEMS Microbiol. Lett. 2005, 248, 241. (f) Gardiner, D. M.; Cozijnsen, A. J.; Wilson, L. M.; Pedras, M. S.; Howlett, B. J. Mol. Microbiol. 2004, 53, 1307.

(3) (a) Borthwick, A. D. Chem. Rev. 2012, 112, 3641. (b) Huang, R.; Zhou, X.; Xu, T.; Yang, X.; Liu, Y. Chem. Biodiversity 2010, 7, 2809.

(4) (a) Trown, P. W.; Bilello, J. A. Antimicrob. Agents Chemother. 1972, 2, 261. (b) Stillwell, M. A.; Magasi, L. P.; Strunz, G. M. Can. J. Microbiol. 1974, 20, 759. (c) DeVault, R. L.; Rosenbrook, W., Jr J. Antibiot. 1973, 26, 532. (d) Li, L.; Li, D.; Luan, Y.; Gu, Q.; Zhu, T. J. Nat. Prod. 2012, 75, 920.

(5) Isolation reports: Acetylaranotin: (a) Neuss, N.; Boeck, L. D.; Brannon, D. R.; Cline, J. C.; DeLong, D. C.; Gorman, M.; Huckstep, L. L.; Lively, D. H.; Mabe, J.; Marsh, M. M.; Molloy, B. B.; Nagarajan, R.; Nelson, J. D.; Stark, W. M. Antimicrob. Agents Chemother. 1968, 213. (b) Trown, P. W.; Lindh, K. P.; Milstrey, K. P.; Gallo, V. M.; Mayberry, B. R.; Lindsay, H. L.; Miller, P. A. Antimicrob. Agents Chemother. 1968, 225. (c) Nagarajan, R.; Huckstep, L. L.; Lively, D. H.; Delong, D. C.; Marsh, M. M.; Neuss, N. J. Am. Chem. Soc. 1968, 90, 2980. (d) Nagarajan, R; Neuss, N.; Marsh, M. M. J. Am. Chem. Soc. 1968, 90, 6518. (e) Cosulich, D. B.; Nelson, N. R.; Van den Hende, J. H. J. Am. Chem. Soc. 1968, 90, 6519. Gliotoxin: (f) Johnson, J. R; Bruce, W. F.; Dutcher, J. D. J. Am. Chem. Soc. 1943, 65, 2005. (g) Bell, M. R.; Johnson, J. R.; Wildi, B. S.; Woodward, R. B. J. Am. Chem. Soc. 1958, 80, 1001. Acetylapoaranotin: (h) Neuss, N.; Nagarajan, R.; Molloy, B. B.; Huckstep, L. L. Tetrahedron Lett. 1968, 9, 4467. Emethallicin E: (i) Kawahara, N.; Nowaza, K.; Yamazaki, M.; Nakajima, S.; Kawai, K. Heterocycles 1990, 30, 507. Epicorazine A: (j) Deffieux, G.; Baute, M.-A.; Baute, R.; Filleau, M.-J. J. Antibiot. 1978, 31, 1102.

(6) (a) Fukuyama, T.; Nakatsuka, S.-I.; Kishi, Y. Tetrahedron 1981, 37, 2045. (b) Fukuyama, T.; Kishi, Y. J. Am. Chem. Soc. 1976, 98, 6723.

(7) Synthetic studies toward gliotoxin and related cyclohexadienol and cyclohexadienone ETPs: (a) Zipfel, H. F.; Carreira, E. M. Chem. Eur. J. 2015, 21, 12475. (b) McMahon, T. C.; Stanley, S.; Kazyanskaya, E.; Hung, D.; Wood, J. L. Tetrahedron Lett. 2011, 52, 2262. (c) Feng, M.; Jiang, X. Chem. Commun. 2014, 50, 9690.

(8) (a) Nicolaou, K. C.; Lu, M.; Totokotsopoulos, S.; Heretsch, P.; Giguere, D.; Sun, Y.-P.; Sarlah, D.; Nguyen, T. H.; Wolf, I. C.; Smee, D. F.; Day, C. W.; Bopp, S.; Winzeler, E. A. J. Am. Chem. Soc. 2012, 134, 17320. (b) Nicolaou, K. C.; Totokotsopoulos, S.; Giguere, D.; Sun, Y.; Sarlah, D. J. Am. Chem. Soc. 2011, 133, 8150.

(9) Codelli, J. A.; Puchlopek, A. P.; Reisman, S. E. J. Am. Chem. Soc. 2012, 134, 1930.

(10) Synthetic studies toward dihydrooxepine ETPs: (a) Gross, U.; Nieger, M.; Bräse, S. Chem. - Eur. J. 2010, 16, 11624. (b) Peng, J. B.; Clive, D. L. J. J. Org. Chem. 2009, 74, 513. (c) Peng, J. B.; Clive, D. L. J. Org. Lett. 2007, 9, 2939. (d) Goodman, R. M.; Kishi, Y. J. Am. Chem. Soc. 1998, 120, 9392. (e) Cebon, B. I. M. Ph.D. Thesis, University of Melbourne, November 2009. (f) Nicolaou, K. C.; Yu, R.; Shi, L.; Cai, Q.; Lu, M.; Heretsch, P. Org. Lett. 2013, 15, 1994. (g) Cameron, A.; Fisher, B.; Fisk, N.; Hummel, J.; White, J. M.; Krenske, E. H.; Rizzacasa, M. A. Org. Lett. 2015, 17, 5998. (h) Belov, D. S.; Ratmanova, N. K.; Andreev, I. A.; Kurkin, A. V. Chem. - Eur. J. 2015, 21, 4141. Also see ref 11 .

(11) (a) Fujiwara, H.; Kurogi, T.; Okaya, S.; Okano, K.; Tokuyama, H. Angew. Chem., Int. Ed. 2012, 51, 13062. The Tokuyama group has also reported a synthesis of MPC1001B: (b) Kurogi, T.; Okaya, S.;
Fujiwara, H.; Okano, K.; Tokuyama, H. Angew. Chem., Int. Ed. 2016, $55,283$.

(12) (a) Kim, J.; Ashenhurst, J. A.; Movassaghi, M. Science 2009, 324, 238. (b) Iwasa, E.; Hamashima, Y.; Fujishiro, S.; Higuchi, E.; Ito, A.; Yoshida, M.; Sodeoka, M. J. Am. Chem. Soc. 2010, 132, 4078. (c) Kim, J.; Movassaghi, M. J. Am. Chem. Soc. 2010, 132, 14376. (d) DeLorbe, J. E.; Jabri, S. Y.; Mennen, S. M.; Overman, L. E.; Zhang, F.-L. J. Am. Chem. Soc. 2011, 133, 6549. (e) Coste, A.; Kim, J.; Adams, T. C.; Movassaghi, M. Chem. Sci. 2013, 4, 3191. (f) DeLorbe, J. E.; Horne, D.; Jove, R.; Mennen, S. M.; Nam, S.; Zhang, F.-L.; Overman, L. E. J. Am. Chem. Soc. 2013, 135, 4117.

(13) Choi, E. J.; Park, J.-S.; Kim, Y.-J.; Jung, J.-H; Lee, J. K.; Kwon, H. C.; Yang, H. O. J. Appl. Microbiol. 2011, 110, 304.

(14) (a) Kim, H. Y.; Shih, H.-J.; Knabe, W. E.; Oh, K. Angew. Chem., Int. Ed. 2009, 48, 7420. For a review on Cu-catalyzed asymmetric 1,3dipolar cycloadditions, see: (b) Stanley, L. M.; Sibi, M. P. Chem. Rev. 2008, 108, 2887.

(15) Lim, A. D.; Codelli, J. A.; Reisman, S. E. Chem. Sci. 2013, 4, 650.

(16) Garber, S. B.; Kingsbury, J. S.; Gray, B. L.; Hoveyda, A. H. J. Am. Chem. Soc. 2000, 122, 8168.

(17) The use of more common conditions, such as aq $\mathrm{LiOH}$, resulted in lower yields due to poor conversion and low recovery of product. Nicolaou, K. C.; Estrada, A. A.; Zak, M.; Lee, S. H.; Safina, B. S. Angew. Chem., Int. Ed. 2005, 44, 1378.

(18) The arene side product was formed in $43 \%$ yield. See Supporting Information for details.

(19) The characterization data $\left({ }^{1} \mathrm{H}\right.$ NMR, ${ }^{13} \mathrm{C}$ NMR, HRMS, optical rotation) are fully consistent with the previously reported isolation data.

(20) Zhang, Y.-G.; Liu, S.-C.; Che, Y.-S.; Liu, X.-Z. J. Nat. Prod. 2007, $70,1522$. 